Authors have nothing to disclose with regard to commercial support. Support was provided solely from institutional or departmental sources.

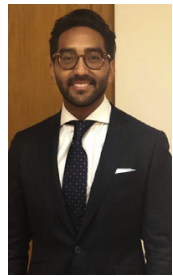

\section{SHOULD KIDNEY OXYGEN SATURATION BE MONITORED TO PREVENT ACUTE KIDNEY INJURY AFTER ADULT CARDIAC SURGERY? \\ To the Editor:}

We are pleased to read the commentary by Ferraris ${ }^{1}$ entitled "Should We Rely on Receiver Operating Characteristic Curves? From Submarines to Medical Tests, the Answer Is a Definite Maybe!" regarding our recently published article. ${ }^{2}$ We would like to clarify some important issues related to our findings. A decrease in kidney oxygen saturation $\left(\mathrm{kSo}_{2}\right)$ less than $65 \%$ and a decline of greater than $20 \%$ from the baseline value during the postoperative stage were identified as independent predictors of cardiac surgery-associated acute kidney injury (CSA-AKI), but not a decline of more than $20 \%$ in baseline serum creatinine.

CSA-AKI remains a severe complication and one of the stronger risk factors for death in patients undergoing cardiac surgery. Scientific advancements in developing universal predictor scales or finding the ideal biomarkers have had limited success. ${ }^{3}$ For this reason, the addition of $\mathrm{kSo}_{2}$ to biomarkers could significantly allow real-time monitoring and thus improve CSA-AKI detection.

Regarding Ferraris' queries, there are evidence-based interventions to improve $\mathrm{kSo}_{2}$ and therefore prevent CSAAKI, such as the restoration of mean arterial pressure from 60 to $75 \mathrm{~mm} \mathrm{Hg}$ - an intervention that improves renal oxygen delivery, glomerular filtration rate, and $\mathrm{kSo}_{2}$. The pressure-dependent kidney perfusion, filtration, and oxygenation at levels of mean arterial pressure below $75 \mathrm{~mm} \mathrm{Hg}$ reflect a relatively exhausted kidney autoregulatory reserve. ${ }^{4}$ However, there are few data relating to kidney oxygen consumption, renal blood flow, and glomerular filtration rate, and current views on $\mathrm{kSo}_{2}$ are presumptive and mostly based on experimental studies. Likewise, we seize this letter to answer all questions raised by Ferraris ${ }^{1}$ that other readers might share (Table 1 ).

All in all, considering that $\mathrm{kSo}_{2}$ provides information about regional oxygen metabolism along with an estimation of kidney perfusion, in addition to its role as a novel marker for AKI after adult cardiac surgery, $\mathrm{kSo}_{2}$ should be carefully monitored in older, frailer, high-risk patients undergoing complex cardiac procedures.

Christian Ortega-Loubon, MD, MEd, PhD
Inmaculada Fierro, $P h D^{b}$
Eduardo Tamayo, MD, PhD
aepartment of Cardiac Surgery and
${ }^{c}$ Anesthesiology and Critical Care
Clinic University Hospital of Valladolid
Valladolid, Spain
${ }^{b}$ Department of Health Science
Universidad Europea Miguel de Cervantes
Valladolid, Spain

\section{References}

1. Ferraris VA. Should we rely on receiver operating characteristic curves? From submarines to medical tests, the answer is a definite maybe! J Thorac Cardiovasc Surg. 2019;157:2354-5.

2. Ortega-Loubon C, Fernandez-Molina M, Fierro I, Jorge-Monjas P, Carrascal Y, Gomez-Herreras JI, et al. Postoperative kidney oxygen saturation as a novel marker for acute kidney injury after adult cardiac surgery. J Thorac Cardiovasc Surg. 2019;157:2340-51.

3. Ortega-Loubon C, Fernandez-Molina M, Paneda-Delgado L, Jorge-Monjas P, Carrascal Y. Predictors of postoperative acute kidney injury after coronary artery bypass graft surgery. Braz J Cardiovasc Surg. 2018;33:323-9.

4. Ricksten SE, Bragadottir G, Redfors B. Renal oxygenation in clinical acute kidney injury. Crit Care. 2013;17:221.

5. Ortega-Loubon C, Fernandez-Molina M, Jorge-Monjas P, Fierro I, HerreraCalvo G, Tamayo E. The relevance of renal oxygen saturation over other markers in cardiac surgery-associated acute kidney injury. J Cardiothorac Vasc Anesth. September 27, 2018 [Epub ahead of print].

6. Deschamps A, Hall R, Grocott H, Mazer CD, Choi PT, Turgeon AF, et al. Cerebra oximetry monitoring to maintain normal cerebral oxygen saturation during highrisk cardiac surgery: a randomized controlled feasibility trial. Anesthesiology. 2016;124:826-36.

7. Ortega-Loubon C, Fernandez-Molina M, Carrascal-Hinojal Y, Fulquet-Carreras E Cardiac surgery-associated acute kidney injury. Ann Card Anaesth. 2016;19 687-98.

8. Lacroix S, Gayda M, Gremeaux V, Juneau M, Tardif JC, Nigam A. Reproducibility of near-infrared spectroscopy parameters measured during brachial artery occlusion and reactive hyperemia in healthy men. J Biomed Opt. 2012;17:077010.

https://doi.org/10.1016/j.jtcvs.2019.05.012 
TABLE 1. Information about kidney oxygen saturation and acute kidney injury

\begin{tabular}{ccc}
\hline Question & Relevance & Response \\
\hline Is $\mathrm{kSO}_{2}$ a "predictor" of AKI? & $\begin{array}{c}\text { To be a valuable predictor, } \\
\text { it is best to know the predictor } \\
\text { value before the outcome. }\end{array}$ & $\begin{array}{c}\mathrm{kSo}_{2} \text { is indeed an independent predictor of AKI, as shown via the } \\
\text { multivariable logistic regression analysis. } \\
\text { Considering that the peak of } \mathrm{SCr} \text { could appear even } 7 \text { days after the } \\
\text { surgery, which is included in the } \mathrm{KDIGO} \text { Criteria for CSA-AKI, and } \\
\text { that } \mathrm{kSo}_{2} \text { was only measured during the first } 48 \mathrm{~h} \text { postoperatively, } \\
\mathrm{kSo}_{2} \text { certainly predicts the possible outcome of CSA-AKI. }\end{array}$ \\
\end{tabular}

How frequently should $\mathrm{kSO}_{2} \quad$ Is it practical to have real-time
be measured?
measurements of $\mathrm{kSo}_{2}$ ?

$\mathrm{kSO}_{2}$ should be measured especially in older patients and in high-risk surgeries with both long $\mathrm{CPB}$ and aortic crossclamp times. What is more, $\mathrm{KSO}_{2}$ needs to be monitored not only during the surgery but also during the postoperative span, when there are several factors that still contribute to the appearance of CSA-AKI.

It is practical to continuously record $\mathrm{kSO}_{2}$ because $\mathrm{kSo}_{2}$ real-time measurement predicts CSA-AKI. Unlike renal biomarkers, which represent the most sensitive means of CSA-AKI early detection but cannot be measured continuously, NIRS enables noninvasive, realtime monitoring and serves as a suitable target for the goal-directed therapy to treat impairments in kidney oxygen supply-demand balance. $^{5}$

$\begin{array}{cc}\begin{array}{c}\text { Are abnormal values of } \\ \mathrm{kSo}_{2} \text { actionable? }\end{array} & \begin{array}{c}\text { Is it practical to intervene to improve } \\ \mathrm{kSo}_{2} \text { (eg, increase oxygen content, } \\ \text { transfuse, and increase red cell mass)? }\end{array}\end{array}$

Absolutely. Actions must be taken to enhance $\mathrm{kSo}_{2}$, such as improve MAP, treat abnormal systemic saturation, correct hypoventilation, and consider RBC transfusion depending on an established algorithm to reverse desaturation. ${ }^{6}$

In fact, it is practical to improve $\mathrm{kSO}_{2}$ levels, because a decrease in $\mathrm{kSO}_{2}$ $<65 \%$ threshold value or a decline of $>20 \%$ from the baseline value is significantly associated with CSA-AKI. As such, avoiding these desaturation levels, CSA-AKI could be prevented.

\begin{abstract}
What factors affect CSA-AKI? Are they different from these affecting non-CSA-AKI?

\section{Validation of CSA-AKI test} results is essential.
\end{abstract}

Risk factors associated with CSA-AKI are multiple. Noncardiac surgery is not an exception. Moreover, cardiac surgery adds renal hypoperfusion, hemodilution, and inflammatory response caused by CPB. It is unlikely that a single etiologic factor will cause AKI. It is rather the consequence of the interaction of multiple factors, not only preoperative but also intraoperative and even postoperative factors.

Numerous studies have proved the close relationship between intraoperative $\mathrm{bSO}_{2}$ and $\mathrm{kSO}_{2}$ decline with postoperative cognitive decline and CSA-AKI, respectively. Although validated levels of $\mathrm{kSO}_{2}$ were lacking, this study has identified critical $\mathrm{kSO}_{2}$ measurements associated with CSA-AKI.

How reproducible are $\mathrm{kSo}_{2}$ measurements?

\footnotetext{
Are tools for measurements of The authors constructed unique $\mathrm{kSO}_{2}$ during $\mathrm{CPB}$ available? equipment to measure $\mathrm{kSO}_{2}$ during CPB. There needs to be some "catch-up" in technology.
}

NIRS parameters are highly reproducible, which enables them to study the microvascular function. ${ }^{8} \mathrm{kSo}_{2}$ measurements are affected by its depth of penetration, conjugated bilirubin, skin pigment, and external source of light.

Depending on each hospital's economic resources, NIRS is usually available. In fact, in most cases, it is often used is cardiac surgery for $\mathrm{bSO}_{2}$ monitoring. $\mathrm{bSo}_{2}$ and $\mathrm{kSO}_{2}$ were measured using the same NIRS sensors; no extra or different equipment was required to measure $\mathrm{kSO}_{2}$.

\footnotetext{
More investigations should be conducted to develop algorithms to correct $\mathrm{kSO}_{2}$ desaturations, in the same way as algorithms are applied to treat $\mathrm{bSo}_{2}$ desaturations.

What interventions can improve How reliable are interventions aimed $\mathrm{kSO}_{2}$ during $\mathrm{CPB}$ ? 